\title{
Peringatan Otomatis Pada Internet of Things Sistem Deteksi Smart Motion
}

\author{
Nizirwan Anwar ${ }^{1}$, Budi Tjahjono ${ }^{2}$, Masmur Tarigan ${ }^{3}$, Dewanto Adhy \\ Rosian $^{4}$, Nur Widiyasono ${ }^{5}$ Rudi Hermawan ${ }^{6}$ \\ ${ }^{1,2,3}$ Fakultas Ilmu Komputer, Universitas Esa Unggul Jakarta Indonesia \\ 4, 5, ${ }^{6}$ Mitra Riset, Inovasi dan Kolaborasi \\ Email : ${ }^{1}$ nizirwan.anwar@esaunggul.ac.id, ${ }^{2}$ budi.tjahjono@esaunggul.ac.id, \\ masmur.tarigan@esaunggul.ac.id, ${ }^{4}$ dewanto72@gmail.com, \\ nur.w095@gmail.com, ${ }^{6}$ rudihermawan567@ gmail.com
}

\begin{abstract}
Abstrak - Masalah utama dalam penelitian ini adalah meningkatnya kasus pencurian dan perampokan. Kejadian ini disebabkan oleh kesibukan setiap orang dalam kesehariannya sehingga lupa akan keamanan rumahnya. Sistem keamanan rumah berbasis Internet of Things (IoT) yang memanfaatkan sensor PIR sebagai pendeteksi gerak manusia kemudian mengirimkan notifikasi berupa notifikasi melalui SMS atau e-mail merupakan salah satu solusi untuk mengatasi masalah yang telah diajukan sebelumnya pada penelitian sebelumnya. Namun, untuk lebih memperjelas peringatan yang dikirim dari sistem tersebut, diperlukan sistem keamanan rumah yang dapat melampirkan gambar pada notifikasi tersebut. Dalam penelitian ini dikembangkan sistem keamanan rumah berbasis IoT. Sistem keamanan IoT yang dikembangkan, dapat secara otomatis mengirimkan pesan peringatan dengan melampirkan gambar saat sensor PIR mendeteksi keberadaan manusia. Sistem IoT membutuhkan Raspberry Pi sebagai mikrokontroler yang telah terkoneksi dengan internet, sensor PIR untuk mendeteksi pergerakan manusia dan Pi Camera untuk memenangkan gambar ketika ada perjumpaan dengan manusia yang berada dalam jangkauan sensor PIR. Eksperimen pada penelitian tersebut menunjukkan bahwa sistem IoT dapat secara otomatis mengirimkan pesan peringatan melalui aplikasi Telegram dengan melampirkan gambar ketika sensor PIR mendeteksi keberadaan manusia dalam berbagai kondisi cahaya dengan jarak 0-5 meter dan kecepatan pengiriman email alert dipengaruhi oleh kondisi koneksi jaringan internet dan ukuran file gambar yang dikirim.
\end{abstract}

Kata kunci - Peringatan, Gambar, IoT, Sensor PIR, Raspberry Pi

\section{Pendahuluan}

Persentase desa yang mengalami kasus pencurian selama tahun 2018 berada pada kisaran 11,42 - 73,76 persen dari total desa di Indonesia [1]. Berdasarkan Data Badan Pusat Statistik, kasus pencurian yang paling signifikan terjadi di Provinsi Jawa Barat dengan persentase sebesar 27,76 persen termasuk pencurian atau pembobolan. Kejadian ini dapat disebabkan oleh aktivitas seharihari setiap orang yang mengakibatkan keamanan rumah terabaikan [2].

Solusi untuk mengatasi masalah keamanan rumah telah dilakukan pada penelitian sebelumnya yaitu pembuatan sistem keamanan berbasis IoT. Penelitian [2], [3], [4], [5], [6] menjelaskan deteksi gerakan manusia dengan bantuan sensor PIR, kamera IP, dan aplikasi smart cam berdasarkan deteksi gerakan otomatis kemudian mengirimkan alarm di berupa alarm, notifikasi SMS dan notifikasi email real-time kepada pemilik rumah. Hanya saja belum adanya sistem keamanan yang ada IP Camera tidak digunakan untuk mengambil gambar saat gerakan manusia terdeteksi oleh sensor PIR yang kemudian dilampirkan pada pesan sebagai peringatan. Kekurangan lainnya adalah tidak ada gambar yang dikirim ke SMS atau notifikasi email. Pemilik rumah tidak dapat melihat atau membedakan pemberitahuan dari orang yang tidak dikenal atau orang yang dikenal. Dalam IoT, segala sesuatu diharapkan dapat saling berinteraksi dan berkomunikasi, seperti saling bertukar data dan informasi terkait kondisi lingkungan. Dengan demikian, IoT bereaksi secara otonom terhadap peristiwa atau peristiwa di lingkungan dan menyediakan layanan dengan atau tanpa campur tangan 
manusia langsung [6]. Pengembangan sistem keamanan rumah berbasis IoT menjadi solusi untuk mengatasi kekurangan penelitian sebelumnya.

Sistem keamanan IoT memungkinkan untuk mengontrol dan memantau kondisi rumah dari jarak jauh secara real time melalui jaringan internet [7][8]. Salah satu tantangan yang akan diselesaikan terkait dengan pengembangan sistem keamanan berbasis IoT yaitu proses otomatisasi pengiriman pesn peringatn dengan melampirkan gambar yang diambil oleh Pi Camera saat sensor PIR mendeteksi keberadaan manusia dan mengetahui hal-hal yang mempengaruhi pengiriman pesan peringatan yang melampirkan gambar.

Raspberry Pi (Raspy) adalah mikrokontroler yang digunakan dalam sistem keamanan ini dan juga server untuk mengirimkan email peringatan [9]. Memanfaatkan layanan email dalam mengirimkan notifikasi saat ini dirasa paling efektif dibandingkan dengan penggunaan layanan SMS karena pengguna layanan SMS semakin berkurang terutama di provider Indosat [10]. Raspy yang digunakan dilengkapi dengan modul Wi-Fi dan ditambahkan modul lain yaitu sensor PIR untuk mendeteksi pergerakan manusia. Seperti halnya indera manusia, sensor dapat merasakan lingkungan [11]. Sensor PIR ini dapat menyaring panjang gelombang cahaya infra merah pasif antara 8 sampai 14 mikrometer, gelombang cahaya infra merah pasif yang dihasilkan dari tubuh manusia berkisar antara 9 sampai 10 mikrometer sedangkan yang dihasilkan oleh hewan berukuran nanometer [12]. Raspy juga dilengkapi dengan modul Pi Camera untuk menangkap gambar saat gerakan manusia berada dalam jangkauan sensor PIR pada jarak 0 hingga 5 meter.

\section{METODE PENELITIAN}

\subsection{Studi Literatur}

Penelitian [2], menyajikan arsitektur yang berhubungan dengan keamanan rumah dan beberapa tempat terlarang seperti area tentara, tempat pemerintahan dan pribadi dll. Selain itu, pemilik / administrator dapat memperoleh peringatan email.

Penelitian [3], sensor PIR dapat mendeteksi gerakan, webcam dapat menangkap objek, dan sistem mengirimkan notifikasi ke smartphone pada jarak maksimum 5,5 meter, dan buzzer dapat langsung diaktifkan saat gerakan terdeteksi.

Penelitian [4] [14], mengimplementasikan sistem keamanan rumah berbasis IoT untuk memantau keadaan rumah yang menggunakan sensor PIR untuk mendeteksi pergerakan manusia dan kemudian mengirimkan notifikasi email ke pemilik rumah saat sensor PIR mendeteksi adanya pergerakan.

Penelitian [5], membangun sistem keamanan dengan menggunakan fitur pelaporan berbasis SMS gateway. Sistem ini dibangun dengan memiliki tiga pengguna yaitu pemilik rumah, satpam, dan admin sebagai pengelola. Fitur pelaporan pada tampilan pemilik rumah terdiri dari 4 jenis pelaporan yaitu kebakaran, pencurian, pembunuhan, dan darurat. Cara kerja sistem adalah ketika satu laporan terjadi, pemilik rumah dan satpam akan mendapat SMS peringatan.

Penelitian [6], membangun sistem rumah pintar yang mampu mengendalikan semua perangkat listrik seperti TV, kipas angin, tabung listrik, lemari es, dan mesin cuci. Sistem juga mampu memberikan notifikasi kepada pengguna tentang segala kesalahan atau kerusakan yang terjadi pada perangkat dengan mengirimkan email atau SMS.

Berdasarkan tabel 1 perbandingan studi terkait, perbandingan atau perbedaan penelitian yang dilakukan dengan penelitian sebelumnya terdapat notifikasi, di mana penelitian yang dilakukan mengembangkan notifikasi yang dikirim melalui email dengan melampirkan gambar sebagai pesan peringatan. 
Tabel 1 Perbandingan Penelitian Terkait

\begin{tabular}{|c|c|c|c|c|c|c|c|c|c|}
\hline \multirow{4}{*}{$\begin{array}{l}\text { Peneliti } \\
\text { (Thanun) } \\
\\
\begin{array}{l}\text { Pooja A. } \\
\text { Dhobi, Niraj } \\
\text { Tevar } \\
\text { (2018) }\end{array} \\
\end{array}$} & \multicolumn{9}{|c|}{ Ruang Lingkup Riset } \\
\hline & \multicolumn{2}{|c|}{ Modul } & \multicolumn{3}{|c|}{ Notifikasi } & \multicolumn{4}{|c|}{ Platform } \\
\hline & \multirow{2}{*}{\begin{tabular}{|c}
$\begin{array}{c}\text { Came } \\
\text { ra }\end{array}$ \\
-
\end{tabular}} & \multirow[t]{2}{*}{\begin{tabular}{|c|} 
PIR \\
Senso \\
$r$ \\
\end{tabular}} & \multirow{2}{*}{$\frac{\text { SMS }}{\sqrt{ }}$} & \multirow{2}{*}{$\begin{array}{c}\text { Surel } \\
\sqrt{ }\end{array}$} & \multirow{2}{*}{$\begin{array}{c}\begin{array}{c}\text { Surel } \\
\text { (Gambar) }\end{array} \\
-\end{array}$} & \multicolumn{3}{|c|}{ Arduino / Raspberry Pi } & \multirow[t]{2}{*}{$\begin{array}{c}\text { Keamanan } \\
\text { Rumah }\end{array}$} \\
\hline & & & & & & $\begin{array}{c}\text { Arduin } \\
\mathrm{o}\end{array}$ & & - & \\
\hline $\begin{array}{l}\text { S. Tanwar, } \\
\text { P. Pately, K. } \\
\text { Patelzz, S. } \\
\text { Tyagix, N. } \\
\text { Kumar, MS } \\
\text { Obaidat } \\
\text { (2017) } \\
\end{array}$ & v & $\checkmark$ & & $\sqrt{ }$ & - & - & $\begin{array}{c}\text { Raspbe } \\
\text { rry Pi }\end{array}$ & & 1 \\
\hline $\begin{array}{l}\text { Budianingsih } \\
\text {, Agus } \\
\text { Riyanto } \\
\text { (2018) } \\
\end{array}$ & - & - & v & - & - & & - & & $\mathrm{v}$ \\
\hline $\begin{array}{l}\text { Dodon } \\
\text { Yendri, } \\
\text { Rahmi Eka } \\
\text { Putri (2018) }\end{array}$ & 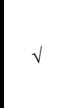 & $\sqrt{ }$ & $\checkmark$ & - & - & - & \begin{tabular}{|} 
Raspbe \\
rry Pi
\end{tabular} & & v \\
\hline $\begin{array}{l}\text { Rajes Khana, } \\
\text { Uus Usnul } \\
\text { (2018) }\end{array}$ & - & - & - & $\sqrt{ }$ & - & $\begin{array}{c}\text { Arduin } \\
\text { o }\end{array}$ & - & & v \\
\hline $\begin{array}{l}\text { Proposed } \\
\text { Research }\end{array}$ & $\sqrt{ }$ & $v$ & - & $\checkmark$ & $\checkmark$ & - & \begin{tabular}{|c|} 
Raspbe \\
rry Pi
\end{tabular} & & v \\
\hline
\end{tabular}

\subsection{Desain Sistem}

Sistem keamanan rumah untuk deteksi gerakan pintar berbasis IoT melibatkan perangkat keras dan perangkat lunak. Sistem ini dirancang untuk dapat mengirim peringatan email dengan melampirkan gambar secara otomatis saat gerakan manusia berada dalam jangkauan sensor PIR. Mengirim peringatan email ke pemilik rumah membutuhkan koneksi jaringan internet. Secara umum hubungan antara perangkat dan jaringan internet diilustrasikan pada Gambar 1.

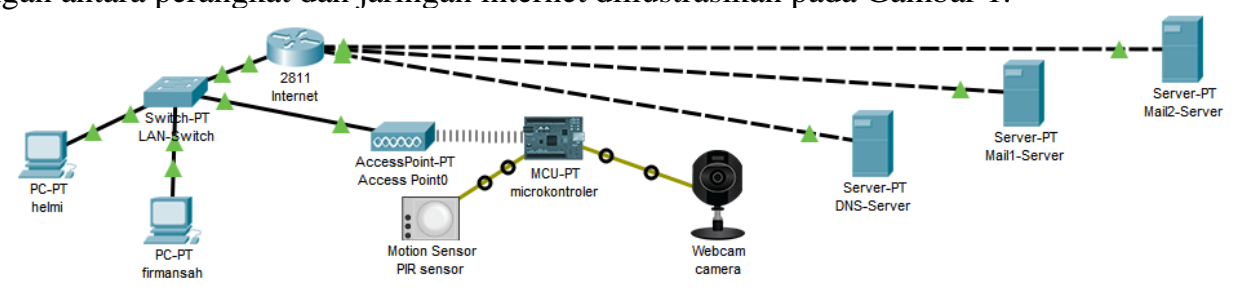

Gambar 1 Topologi Jaringan

Gambar 1 menggambarkan topologi jaringan pada sistem keamanan rumah berbasis IoT yang dikembangkan. Mikrokontroler (raspberry pi) mendapatkan akses internet dari jaringan Wi-Fi yang sudah terkoneksi dengan internet karena raspberry pi secara default sudah dilengkapi dengan modul wi-fi. Protokol yang digunakan untuk komunikasi data menggunakan protokol Transmission Control Protocol (TCP) pada port 55, sedangkan port yang digunakan oleh SMTP untuk mengirim email adalah port 587. Sistem keamanan jaringan dijelaskan pada gambar 2.

Berdasarkan gambar 2, firewall digunakan dalam protokol ICMP, yang diblokir oleh protokol ICMP (ping diblokir). Pastikan konfigurasi perangkat dengan perangkat lain kemudian konfigurasi perangkat dengan jaringan internet dilakukan dengan benar agar sistem dapat bekerja dengan baik. Secara umum perancangan sistem keamanan rumah disajikan pada diagram alir gambar 3 sehingga dapat dipahami berdasarkan urutan tahapan dari satu proses ke proses lainnya. 


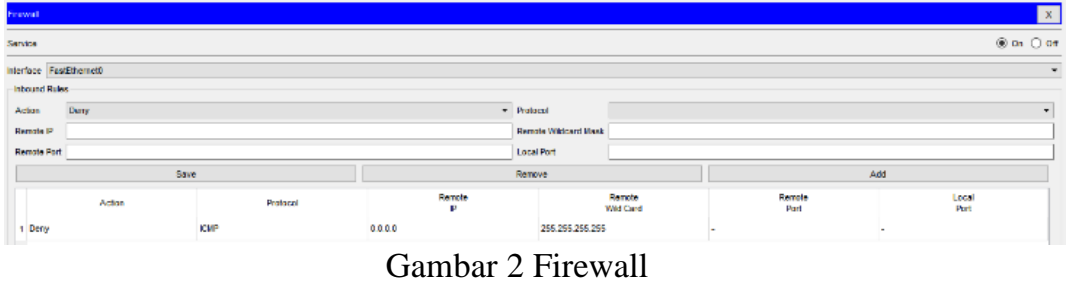

Gambar 2 Firewall

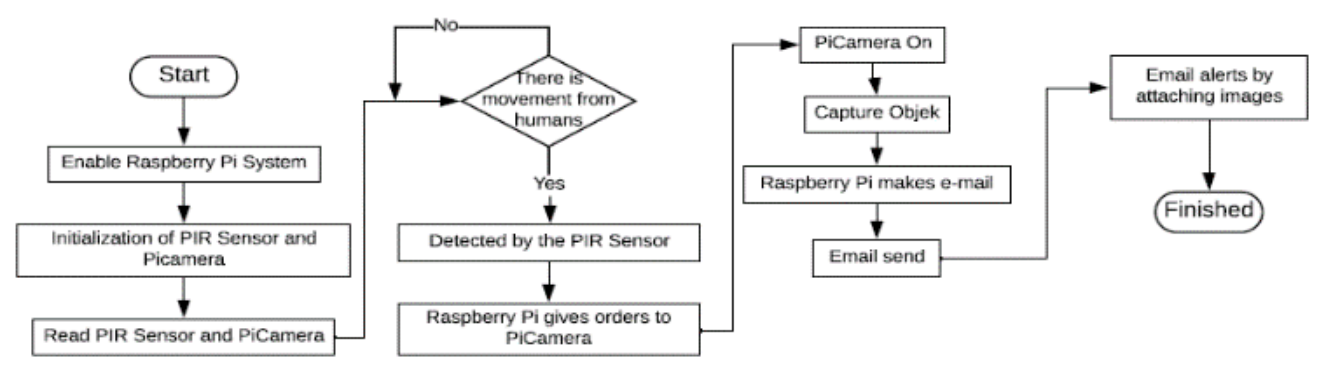

Gambar 3 Diagram Alir

Berdasarkan gambar 3, alur sistem keamanan rumah dimulai dengan mengaktifkan sistem raspberry pi. Sistem akan menginisialisasi sensor Kamera PIR dan Pi dan akan membaca konektivitas dengan sensor Kamera PIR dan Pi karena sistem keamanan rumah menggunakan sensor PIR dan Kamera Pi yang terhubung ke Raspberry Pi. Sensor PIR digunakan untuk mendeteksi keberadaan manusia, dan Pi Camera digunakan untuk menangkap gambar ketika kehadirannya terdeteksi. Setiap kali ada pergerakan orang yang berada dalam jangkauan sensor PIR, Sensor PIR akan memicu Kamera Pi untuk mengambil gambar melalui Raspberry Pi. Raspberry Pi mengirimkan perintah ke Pi Camera untuk mengklik gambar dan menyimpannya. Setelah itu, Raspberry Pi membuat email dan mengirimkannya ke alamat email yang ditentukan dengan gambar yang baru saja Anda klik. Email tersebut berisi pesan dan gambar penyusup sebagai email peringatan.

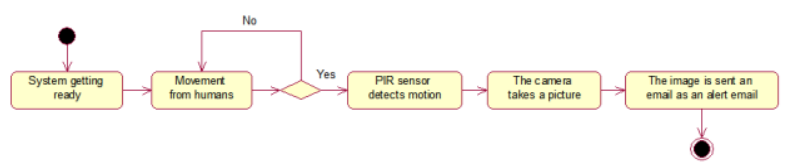

Gambar 4 Diagram Aktivitas

Berdasarkan gambar 4, saat Raspberry Pi disuplai oleh listrik, sistem sudah siap, atau sistem aktif, maka saat ada pergerakan manusia yang masuk ke sensor PIR, gerakan tersebut akan menjadi input yang berharga untuk sensor PIR. dan program akan mendeteksi pergerakan, setiap itu terjadi akan memicu PiCamera untuk mengambil gambar melalui raspberry pi, kemudian gambar tersebut dikirim melalui email ke pemilik rumah sebagai email peringatan.

\section{HASIL DAN PEMBAHASAN}

Ada empat tahapan utama yang dilakukan pada penelitian terkait dengan pengembangan sistem keamanan rumah ini, yaitu: persiapan perangkat keras, persiapan perangkat lunak, konfigurasi sistem, pengujian.

3.1 Persiapan Perangkat Keras

Tahap ini menganalisis perangkat keras yang dibutuhkan dalam pengembangan sistem keamanan rumah berbasis IoT. Secara umum kebutuhan perangkat keras akan disajikan pada tabel 2 dan akan diilustrasikan pada gambar 5 dan prototipe dapat dilihat pada gambar 6 . 
Tabel 2 Kebutuhan Perangkat Keras

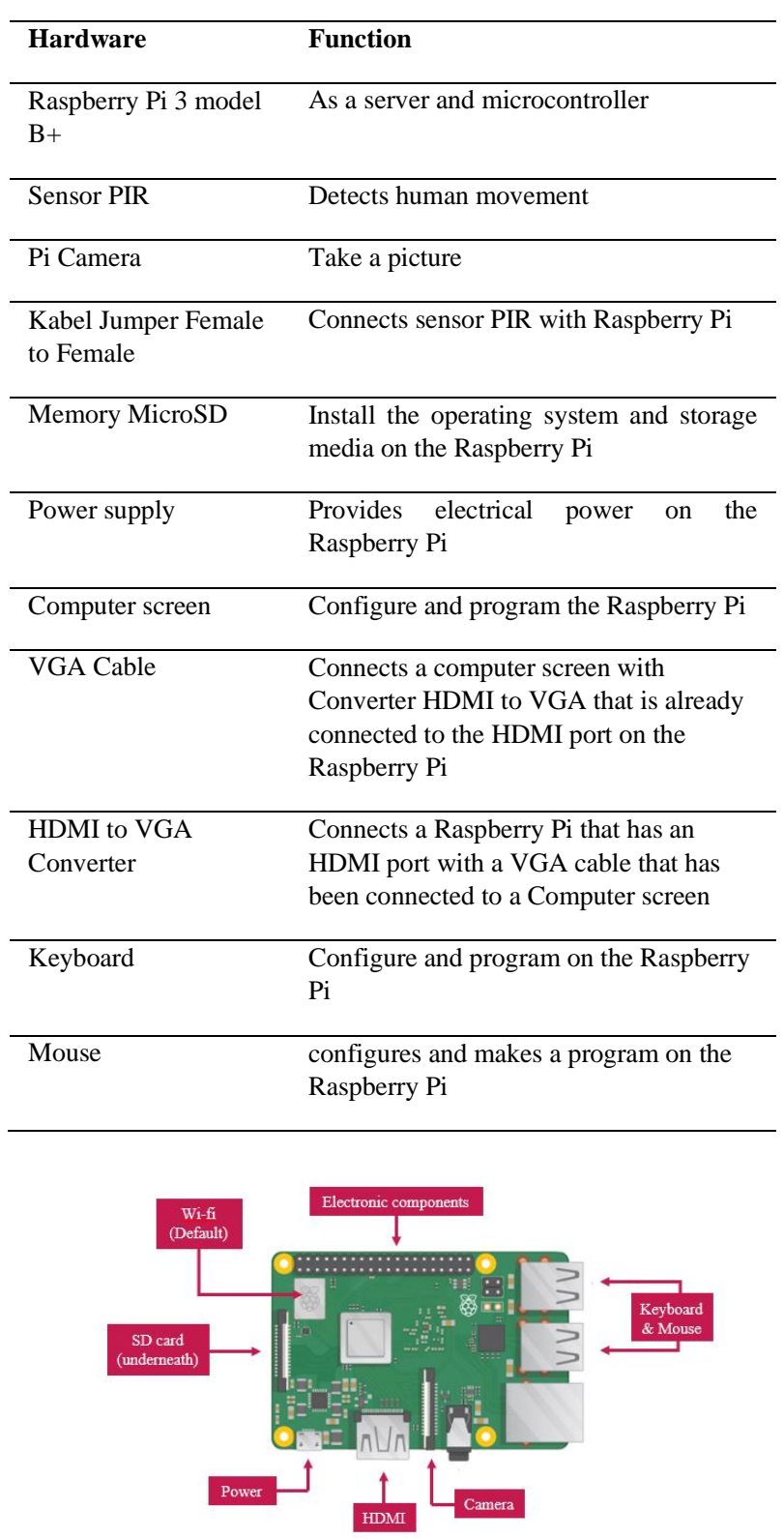

Gambar 5 Ilustrasi desain perangkat keras

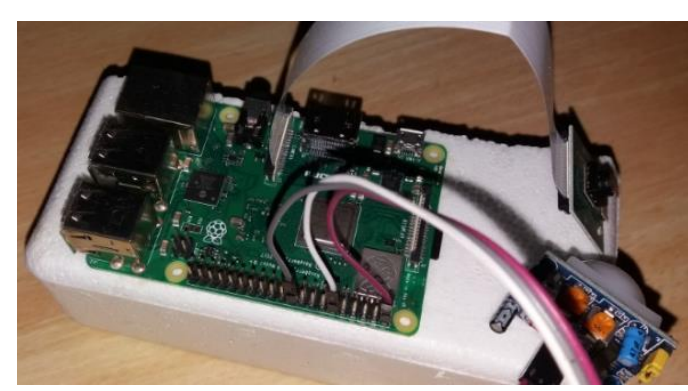

Gambar 6 Purwarupa Sistem Perangkat Keras 


\subsection{Persiapan perangkat lunak}

Tahap ini menganalisis perangkat lunak yang dibutuhkan dalam pengembangan sistem keamanan berbasis IoT. Secara umum kebutuhan perangkat lunak akan disajikan pada tabel 3.

Tabel 3 Kebutuhan Perangkat Lunak

\begin{tabular}{|c|c|}
\hline Software & Function \\
\hline $\begin{array}{l}\text { Operating } \\
\text { System } \\
\text { Windows } 10\end{array}$ & Running software or other applications. \\
\hline $\begin{array}{l}\text { Operating } \\
\text { System } \\
\text { Raspbian } \\
\text { Jessie }\end{array}$ & $\begin{array}{l}\text { The Operating System has been } \\
\text { optimized and is specific to the } \\
\text { Raspberry Pi }\end{array}$ \\
\hline
\end{tabular}

\subsection{Pengujian}

Tahap pengujian dilakukan untuk memastikan bahwa setiap fungsi dan setiap perangkat di sistem ini berfungsi dengan benar. Pengujian dilakukan terhadap beberapa variabel dari sistem keamanan berbasis IoT dan analisisnya. Variabel desain yang akan diuji meliputi pengujian sensor PIR, pengujian pada beberapa kondisi, serta durasi pengiriman dan penerimaan pesan saat pergerakan seseorang terdeteksi

Tabel 4 Data Tes PIR Sensor

\begin{tabular}{|c|c|c|c|c|c|}
\hline \multirow{2}{*}{ Testing } & \multicolumn{5}{|c|}{ Distance (meters) } \\
\hline & 1 & 3 & 5 & 5.1 & 5.2 \\
\hline 1 & Detected & Detected & Detected & $\begin{array}{l}\text { Not } \\
\text { Detected }\end{array}$ & $\begin{array}{l}\text { Not } \\
\text { Detected }\end{array}$ \\
\hline 2 & Detected & Detected & Detected & $\begin{array}{l}\text { Not } \\
\text { Detected }\end{array}$ & $\begin{array}{l}\text { Not } \\
\text { Detected }\end{array}$ \\
\hline 3 & Detected & Detected & Detected & $\begin{array}{l}\text { Not } \\
\text { Detected }\end{array}$ & $\begin{array}{l}\text { Not } \\
\text { Detected }\end{array}$ \\
\hline 4 & Detected & Detected & Detected & $\begin{array}{l}\text { Not } \\
\text { Detected }\end{array}$ & $\begin{array}{l}\text { Not } \\
\text { Detected }\end{array}$ \\
\hline 5 & Detected & Detected & Detected & $\begin{array}{l}\text { Not } \\
\text { Detected }\end{array}$ & $\begin{array}{l}\text { Not } \\
\text { Detected }\end{array}$ \\
\hline
\end{tabular}

Berdasarkan data pengujian pada Tabel 4 yaitu pengujian Sensor PIR, pengujian pada jarak 1-5 meter sensor PIR dapat mendeteksi gerakan manusia sedangkan pengujian pada jarak lebih dari 5 meter sensor PIR tidak dapat mendeteksi gerakan manusia. Kesimpulannya, rentang batas deteksi sensor PIR pada pergerakan manusia berjarak 0 - 5 meter.

Hasil pengujian pada tabel 5 pergerakan manusia pada kondisi terang, kondisi gelap, dan kondisi malam hari namun terdapat cahaya. Hasil pengujian menunjukkan bahwa sistem dapat mendeteksi pergerakan dalam berbagai kondisi pencahayaan, namun kondisi cahaya mempengaruhi kualitas pengambilan gambar. Parameter kondisi terang dan gelap pada pengujian ini mengacu pada hasil penelitian [14]. 
Tabel 5 Pengujian dengan Beragam Kondisi Penerangan

\begin{tabular}{llll}
\hline Light Conditions & PIR Sensor & Pi Camera & Message Alert \\
\hline Light & Detected & $\begin{array}{l}\text { Take a } \\
\text { picture }\end{array}$ & $\begin{array}{l}\text { Send message } \\
\text { alert }\end{array}$ \\
\hline Dark & Detected & $\begin{array}{l}\text { Take a } \\
\text { picture }\end{array}$ & $\begin{array}{l}\text { Send message } \\
\text { alert }\end{array}$ \\
\hline $\begin{array}{l}\text { Night but there } \\
\text { is a light }\end{array}$ & Detected & $\begin{array}{l}\text { Take a } \\
\text { picture }\end{array}$ & Send email alert \\
\hline
\end{tabular}

Table 6 Durasi Pengiriman dan Penerimaan Email

\begin{tabular}{|c|c|c|c|c|}
\hline \multirow[b]{2}{*}{ Testing } & \multicolumn{3}{|c|}{ Time (hour: minute : second) } & \multirow{2}{*}{ File Size } \\
\hline & Sending & $\begin{array}{l}\text { Receive } \\
\text { d }\end{array}$ & Delay & \\
\hline \multirow{2}{*}{1} & $16: 29: 0$ & $16: 29: 2$ & 15 second & $702 \mathrm{~kb}$ \\
\hline & 7 & 2 & & \\
\hline \multirow{2}{*}{2} & $16: 29: 4$ & $16: 30: 0$ & 15 second & 702 kb \\
\hline & 7 & 2 & & \\
\hline \multirow{2}{*}{3} & $16: 30: 1$ & $16: 30: 3$ & 15 second & 702 kb \\
\hline & 7 & 2 & & \\
\hline \multirow{2}{*}{4} & $16: 49: 0$ & $16: 49: 2$ & 17 second & $737 \mathrm{~kb}$ \\
\hline & 3 & 0 & & \\
\hline \multirow{2}{*}{5} & $16: 49: 3$ & $16: 49: 5$ & 17 second & 737 kb \\
\hline & 8 & 5 & & \\
\hline
\end{tabular}

Berdasarkan data uji pada tabel 6 dapat ditarik kesimpulan. Yakni, durasi antara pengiriman dan penerimaan email alert pada pengulangan ke 1 - 3 adalah 15 detik, sedangkan pada pengulangan ke 4 dan 5 adalah 17 detik. Perbedaan ini dapat dipengaruhi oleh perbedaan ukuran file gambar dan kondisi koneksi jaringan internet.

\section{SIMPULAN}

Smart Motion Detection System berbasis IoT telah berhasil diimplementasikan dengan mekanisme pengiriman email alert secara otomatis dengan menambahkan hasil pemotretan saat ada gerakan manusia. Sistem ini dapat bekerja secara optimal pada jarak antara 0-5 meter dengan kondisi cahaya yang bervariasi, namun hal tersebut berpengaruh pada kualitas gambar yang ditangkap. Durasi rata-rata pengiriman email adalah 15 detik tergantung pada kualitas gambar yang diambil oleh Pi Camera. Sehingga respon dari sistem ini masih dikategorikan sebagai real-time.

\section{UCAPAN TERIMA KASIH / ACKNOWLEDGMENT}

Terima kasih kami haturkan kepada pihak yang telah membantu dan mendukung melaksanakan penelitian (research) ini didanai oleh Kementerian Pendidikan Tinggi / Badan Riset dan Inovasi Nasional (BRIN) Deputi bidang penguatan riset dan pengembangan menyusul perubahan kontrak nomor: 225/SP2H/LT/DRPM/2019 dan SK Perubahan BRIN Nomor 25/E1/Kpt/2020 tahun 2020 dengan skema Penelitian Dasar Unggulan Perguruan Tinggi (PTUPT) tahun 2019, dan mengucapkan terima kasih Rektor Universitas Esa Unggul, Kepala LPPM Universitas Esa Unggul, Dekan Fakultas Ilmu Komputer Universitas Esa Unggul, Mitra Penelitian dan kepada pihak lain yang tidak disebutkan satu persatu atas do'a dan dukungan dan bantuannya. 


\section{DAFTAR PUSTAKA}

[1] Subdirektorat Statistik Politik dan Keamanan, "Statistik Kriminal 2018," Badan Pusat Statistik, Indonesia, 2018.

[2] S. Tanwar, P. Pately, K. Patelz, S. Tyagix, N. Kumar and M. Obaidat, "An Advanced Internet of Thing based Security Alert System for Smart Home," IEEE, 2017.

[3] D. Yendri and R. E. Putri, "Sistem Pengontrolan Dan Keamanan Rumah Pintar (Smart Home) Berbasis Android," pp. 1-6, 2018.

[4] R. Khana and U. Usnul, "Rancang Bangun Sistem Keamanan Rumah Berbasis IoT dengan Platform Android," Ejournal Kajian Teknik Elektro Vol.3 No.1, pp. 18-31, 2018.

[5] Budianingsih and A. Riyanto, "Prototipe Sistem Keamanan cerdas pada komplek perumahan," Jurnal Pendidikan Informatika dan Sains, pp. 146-154, 2018.

[6] P. A. Dhobi and N. Tevar, "IoT Based Home Appliances Control," Proceedings of the IEEE 2017 International Conference on Computing Methodologies and Communication, pp. 648-651, 2017.

[7] A. N. Ansari, M. Sedky, N. Sharma and A. Tyagi, "An Internet of things approach for motion detection using Raspberry Pi," in Proceedings of 2015 International Conference on Intelligent Computing and Internet of Things, Harbin, China, 2015.

[8] M. Al-Kuwari, A. Ramadan, Y. Ismael, L. Al-Sughair and A. Gastli, "Smart-Home Automation using IoT-based Sensing and Monitoring Platform," IEEE, 2018.

[9] P. B. Patel, V. M. Choksi, S. Jadhav and M. Potdar, "Smart Motion Detection System using Raspberry Pi," International Journal of Applied Information Systems (IJAIS), vol. 10, no. 5, 2016.

[10] A. Rusli, "Pengguna SMS dan Telepon di Indonesia, Beralih ke Data Internet," Cendana News, 24 Mei 2017. [Online]. Available: https://www.cendananews.com/2017/05/pengguna-sms-dan-telepon-di-indonesia-beralih-kedata-internet.html. [Accessed 25 April 2019].

[11] F. S. Perilla, G. R. V. Jr. and N. M. Cacanindin, "Fire Safety and Alert System Using Arduino Sensors with IoT Integration," ICSCA, 2018.

[12] Dakhi, Herlina and Rini, "Sistem Pemantau Ruang Jarak Jauh Menggunakan Sensor PIR (Passive Infrared) Berbasis Atmega 8535," Repositori Institusi USU, pp. 5-7, 2017.

[13] J.Chandramohan, R.Nagarajan, K.Satheeshkumar, N.Ajithkumar, P.A.Gopinath and S.Ranjithkumar, "Intelligent Smart Home Automation and Security System Using Arduino and Wi-fi," International Journal Of Engineering And Computer Science, vol. 6, no. 3, 2015.

[14] D. Herdiwijaya, "Pengukuran Kecerahan Langit Malam arah Zenith untuk Penentuan Awal," pp. 95-102, 2016. 